\title{
Three-Body Abrasion Corrosion Studies of High-Cr Cast Irons: Benefits and Limitations of Tribo-electrochemical Methods
}

\author{
Grazyna Stachowiak • Mobin Salasi • \\ Gwidon Stachowiak
}

Received: 26 October 2014/Revised: 23 December 2014/Accepted: 11 January 2015/Published online: 27 January 2015

(C) Springer International Publishing AG 2015

\begin{abstract}
High-Cr white cast irons (WCIs) are multiphase alloys commonly used in aqueous industrial environments in applications that require both high abrasion and high corrosion resistance. Various electrochemical techniques can be useful in elucidating tribocorrosion characteristics of metallic materials undergoing wear in a corrosive environment. This study is focused on the interpretation of electrochemical measurements applied to three-body abrasion corrosion contacts of high-Cr WCIs. Particular attention has been paid to determine whether tribo-electrochemical data can pick up any effects that the multiphase microstructure of WCIs may have on the tribocorrosion characteristics, especially in environments containing chloride ions. Since both wear and corrosion of multiphase alloys are usually not uniform, their tribocorrosion behaviour is difficult to study and is still poorly understood. The experimental results are discussed in terms of benefits and limitations of tribo-electrochemical techniques such as polarization (potentiostatic, potentiodynamic) and electrochemical noise (galvanic coupling, potentiostatic) in studying abrasion corrosion behaviour of high-Cr WCIs. The application of high-resolution surface analysis techniques (microprobe, NanoSIMS, C-AFM and SKPFM), used in support of the electrochemical data interpretation, is also demonstrated.
\end{abstract}

Keywords Abrasion corrosion - High-Cr white cast irons · Tribo-electrochemical methods $\cdot$ Surface analysis techniques

G. Stachowiak $(\square) \cdot$ M. Salasi · G. Stachowiak

Department of Mechanical Engineering, School of Civil and Mechanical Engineering, Curtin University, Bentley, WA 6102, Australia

e-mail: Grazyna.Stachowiak@curtin.edu.au

\section{Introduction}

Abrasion corrosion involves combined mechanical and chemical interactions when a material undergoes abrasive wear in a corrosive environment. Research in tribocorrosion has gained attention due to its practical importance and potential economic benefits, as highlighted in two recent book publications $[1,2]$. In the last two decades, various electrochemical techniques have been adapted to tribocorrosion research and significant progress has been made in the interpretation of the tribo-electrochemical data [3-6]. While close attention has been paid to tribocorrosion testing and measurements related to a sliding contact (two-body abrasion), much less is understood about viability of tribo-electrochemical methods for testing three-body abrasion corrosion [6-8]. In sliding tribocorrosion a typical two-body contact involves an inert ball or pin rubbing against a metallic wear sample (working electrode) with reciprocating or unidirectional motion [3-5, 9]. In this configuration, the ratio of wornto-unworn surface area is often low, and during the 'out-ofcontact' or 'non-friction' time the worn area of passive alloys repassivates, at least partially [10]. The most common set-up for investigating three-body abrasion corrosion is an inert ball or disc rotating against the loaded wear sample while the abrasive slurry is delivered to the contact interface [6-8]. The question, not answered yet, is whether the differences between two-body and three-body arrangements could affect the electrochemical measurements and data interpretation.

Despite the growing interest and significant progress in tribocorrosion studies, the testing methodology is largely not standardized [11, 12]. The only current standard, ASTM G119, describes the general method of quantifying synergistic effects of wear and corrosion and is applicable to materials that corrode uniformly [13]. As such the standard's use is limited to those combinations of materials 
and environments where the incidence of, e.g. pitting, crevice or galvanic corrosion is rare, and where interfering reactions such as hydrogen evolution are not a problem when wear is measured under low cathodic potentials [3]. Most measurements based on ASTM G119 are therefore relevant to industrial tribocorrosion cases where the materials have been chosen specifically to avoid localized corrosion. Thus, the application of the standard for multiphase alloys such as high-Cr WCIs must be approached with caution. The authors have shown that depending on the chemistry of aqueous environment, the dissolution rate of different phases can vary significantly $[14,15]$. Also, since it is often not clear which dissolution reactions dominate, conversion of current to mass loss using Faraday's law can be problematic. The shortcomings of ASTM G119 have forced researchers to explore the usefulness of other electrochemical methods for tribocorrosion studies. The application of potentiostatic and potentiodynamic polarization in tribocorrosion studies, although not standardized, has been well documented [3,5]. In contrast, the use of methods such as electrochemical impedance spectroscopy (EIS) and electrochemical noise (EN), the latter especially promising in shedding light on the tribocorrosion of multiphase alloys, has not been formalized yet [1619]. Also, well-researched tribo-electrochemical techniques able to measure in situ localized phenomena are lacking [11]. Special methods such as microcell technique used for static localized corrosion studies are hard to adapt for tribocorrosion conditions [19, 20].

Multiphase high-Cr WCIs are commonly chosen for mining and mineral processing applications, e.g. slurry pumps, where abrasion and/or erosion in aqueous environments occur [21, 22]. Most studies found in the literature have concentrated either on the corrosion behaviour of high-Cr WCIs [23-25] or on their wear characteristics in air and in slurries [21, 26-29]. Only in a few studies the synergistic approach has been used, either based on the ASTM G119 methodology or slightly modified [30-33]. The electrochemical methods applied to study tribocorrosion of high-Cr WCIs have been limited to potentiostatic or potentiodynamic polarization tests [33-36]. The results published have indicated difficulties in studying and interpreting complex interactions that occur in tribocorrosion of multiphase materials.

In the past several years, the authors have studied corrosion and three-body abrasion corrosion behaviour of hypo- and hypereutectic high-Cr WCIs in neutral and alkaline aqueous solutions with aim to provide new insights into the topic [14, 15, 37]. Various electrochemical techniques such as polarization resistance, potentiostatic and potentiodynamic polarization and EN have been tried. The objective was to explore the usefulness of electrochemical measurements in elucidating three-body abrasion corrosion characteristics of multiphase materials containing hard carbides. This paper summarizes the main findings in terms of benefits and limitations of tribo-electrochemical studies of complex microstructures.

\section{Experimental}

\subsection{Three-Body Abrasion Corrosion Tribometer}

Tribocorrosion experiments were carried out on a rotating disc-on-plate tribometer designed to allow simultaneous investigation of three-body abrasive wear and electrochemical corrosion. A schematic diagram of the abrasion corrosion tribometer is shown in Fig. 1 and detailed description of the experimental set-up and its capabilities can be found elsewhere $[8,14]$. Corrosion-only measurements were conducted using the same set-up, with the unloaded sample and without the slurry flow.

As shown in Fig. 1, the tribocorrosion contact consists of a ceramic disc (tetragonal zirconia polycrystal, $R_{\mathrm{a}}=0.1 \mu \mathrm{m}, 1,200 \mathrm{HV}$ ) rotating against a loaded wear sample with the abrasive slurry delivered to the contact interface. The wear sample acts as the working electrode (WE) in a three-electrode cell arrangement, a 15-mmdiameter platinum $(\mathrm{Pt})$ mesh is the counter electrode $(\mathrm{CE})$ and a silver/silver chloride electrode (SSE) inserted in a Luggin tube is the reference electrode (RE). A nominally identical sample, positioned below the wear sample in the loading arm, is used in galvanic coupling tests which aim to monitor EN. The electrodes are connected to Gamry Reference 600 potentiostat/ZRA. The details of electrochemical techniques are described in Sect. 2.3.

\subsection{Materials and Testing Conditions}

As-cast hypereutectic $30 \% \mathrm{Cr}$ white cast iron (30CrWCI), used commercially in slurry pumps, has been chosen as a

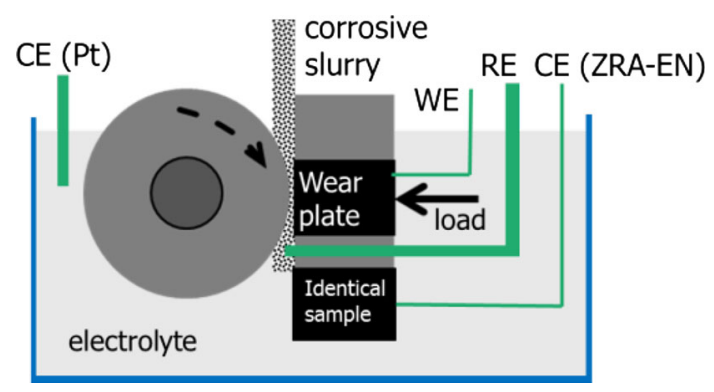

Fig. 1 Schematic diagram of the three-body abrasion corrosion experimental rig; $W E$ working electrode (wear sample), $C E$ counter electrode (either Pt or material nominally identical to the wear sample), $R E$ reference electrode 
wear sample. SEM image of the polished microstructure of 30CrWCI is shown in Fig. 2a and additional material characteristics are given in Table 1 . As can be seen in Fig. 2a, the microstructure of 30CrWCI consists of large primary and small eutectic mixed carbides, predominantly $(\mathrm{Fe}, \mathrm{Cr})_{7} \mathrm{C}_{3}$, in an iron-based austenitic matrix. Crystal structures of the carbides and the matrix were confirmed by the electron backscatter diffraction (EBSD) Kikuchi pattern shown in Fig. $2 b$ and the X-ray diffraction (XRD) spectrum shown in Fig. 2c. EDS spectra in Fig. 2d show the qualitative elemental composition of both phases.

30CrWCI is capable of forming passive films in certain environments [14, 15]. The passive layer forms due to a sufficient amount of chromium in solid solution within the iron-rich matrix $[14,36]$. However, since the microstructure of $30 \mathrm{CrWCI}$ contains a high volume fraction of carbides, about $46 \mathrm{vol} \%$, and the distribution of $\mathrm{Cr}$ in the matrix is nonhomogeneous, the composition and structure of the passive films vary over the surface [37].

12-mm-diameter discs with a 5-mm thickness were cut from commercial 30CrWCI slurry pumps using wire-EDM. The discs were embedded in epoxy resin and electrical connections were provided as required for working electrodes. The exposed surfaces of the working electrodes were then ground and polished, finishing with a $1-\mu \mathrm{m}$ diamond paste. The average surface roughness was $R_{\mathrm{a}}=0.15 \pm 0.03 \mu \mathrm{m}$. Care was taken to ensure that there was a tight seal between the disc and the epoxy mounting eliminating any crevice effects.

Tribo-electrochemical tests were performed in various electrolytes with $\mathrm{pH}$ ranging from near neutral to highly alkaline. All solutions were naturally aerated and their chemical compositions are shown in Table 2. Electrolytes A-C represent typical environments in which high- $\mathrm{Cr}$ (a)

(b)

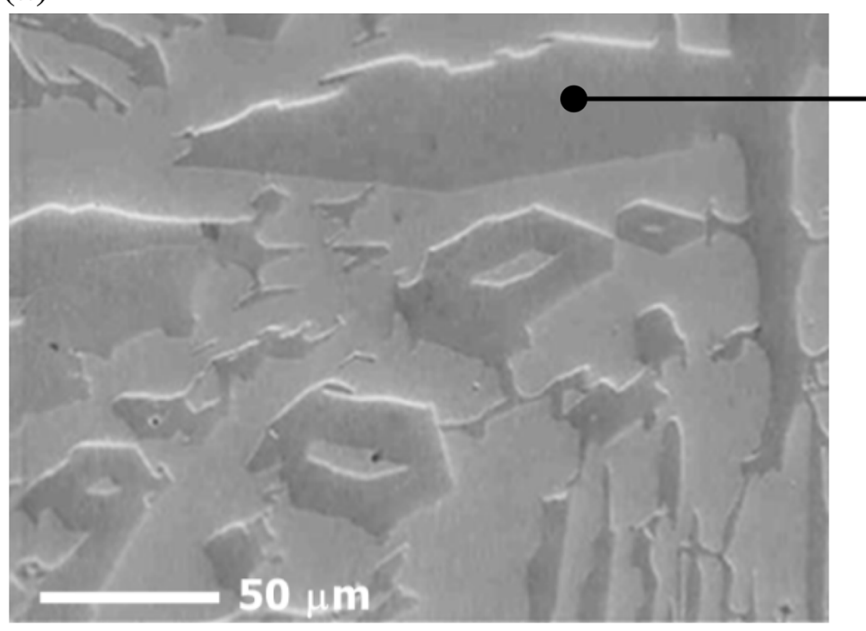

(c)

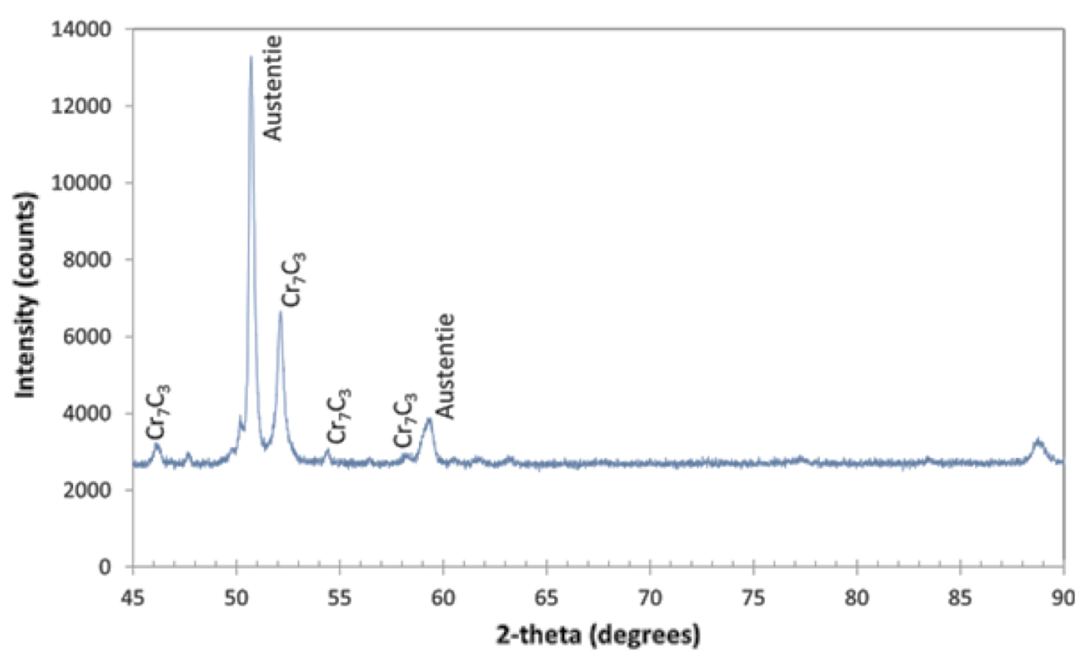

(d)
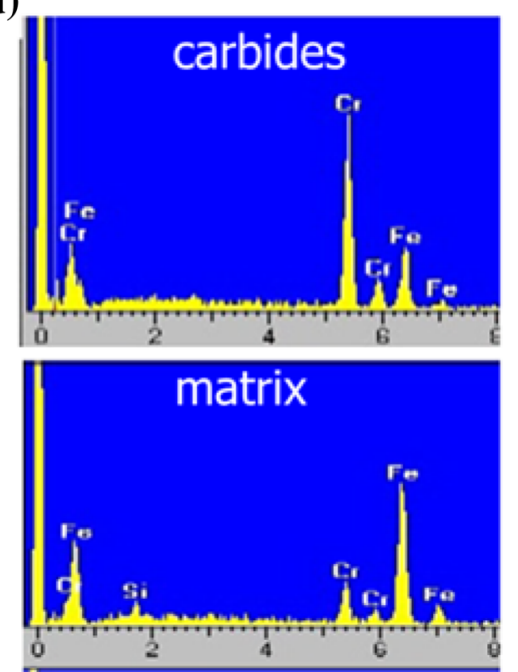

Fig. 2 a SEM micrograph of finely polished surface of 30CrWCI; b EBSD Kikuchi pattern for $\mathrm{Cr}_{7} \mathrm{C}_{3}$ structure; $\mathbf{c}$ XRD spectrum showing structures of main phases; $\mathbf{d}$ qualitative elemental EDS spectra of the carbides and the matrix 
Table 1 Material characteristics of as-cast hypereutectic 30CrWCI

\begin{tabular}{lllll}
\hline $\begin{array}{l}\text { Chemical composition } \\
\text { wt\% }\end{array}$ & $\begin{array}{l}\text { Microhardness } \\
\mathrm{HV}_{0.1}\end{array}$ & Cr:C ratio & $\begin{array}{l}\text { Vol\% Carbides } \\
\text { measured by } \\
\text { Image } \mathrm{J}\end{array}$ & \begin{tabular}{l} 
Average wt\% Cr in matrix \\
\cline { 3 - 5 }
\end{tabular} \\
\hline Fe base, 30Cr, 4.5C & $\begin{array}{l}\text { Measured EDS } \\
\text { barbides: } 1338\end{array}$ & 6.7 & 46 & $\begin{array}{l}\text { Calculated } \\
\text { according } \\
\text { to ref [38] }\end{array}$ \\
\hline
\end{tabular}

Table 2 Composition and nominal $\mathrm{pH}$ of the electrolytes used in corrosion-only and abrasion corrosion experiments

\begin{tabular}{lll}
\hline Electrolyte & Composition & $\mathrm{pH}$ \\
\hline A & $0.01 \mathrm{M} \mathrm{NaOH}$ & 12 \\
B & $0.01 \mathrm{M} \mathrm{NaOH}+500 \mathrm{mg} / \mathrm{l} \mathrm{NaCl}$ & 12 \\
$\mathrm{C}$ & $4.4 \mathrm{M} \mathrm{NaOH}+17.53 \mathrm{~g} / 1 \mathrm{NaCl}+0.2 \mathrm{M} \mathrm{Na}_{2} \mathrm{SO}_{4}+0.4 \mathrm{M} \mathrm{Na}_{2} \mathrm{CO}_{3}$ & $>14$ \\
$\mathrm{D}$ & $17.53 \mathrm{~g} / \mathrm{l} \mathrm{NaCl}+0.2 \mathrm{M} \mathrm{Na}_{2} \mathrm{SO}_{4}+0.4 \mathrm{M} \mathrm{Na}_{2} \mathrm{CO}_{3}$ & $\sim 11$ \\
E & $500 \mathrm{mg} / 1 \mathrm{NaCl}$ & 7.5 \\
\hline
\end{tabular}

WCIs are used in industrial applications. The majority of tests were conducted in $0.01 \mathrm{M} \mathrm{NaOH}$ solution without (electrolyte A) or with chloride ions (electrolyte B). Chloride ions are unavoidable contaminants in many mineral processing slurries and their presence adversely affects the corrosion resistance of passive alloys. The composition of electrolyte $\mathrm{C}$ is similar to that found in the Bayer process liquid. The composition of electrolyte D differs from that of electrolyte $\mathrm{C}$ by the absence of $\mathrm{NaOH}$. Electrolyte E represents near neutral solutions containing the same amount of chloride ions as electrolyte B. All tests were conducted at room temperature of $23 \pm 1{ }^{\circ} \mathrm{C}$. Coarse garnet $(212-300 \mu \mathrm{m})$ or silica sand $(150-212 \mu \mathrm{m})$ particles acted as abrasive grits in the slurries [14, 15].

Various microscopy and chemical analysis techniques were used to examine the wear sample microstructure, surface chemistry and the morphology of worn surfaces, i.e. scanning electron microscopy (SEM, Zeiss Evo 40XVP) with EBSD, X-ray diffraction (XRD, Bruker D8), electron microprobe (EMPA, JEOL 8530F), secondary ion mass spectrometry (Cameca NanoSIMS 50), conductive atomic force microscopy (C-AFM) and scanning Kelvin probe force microscopy (SKPFM) (Dimension 3100) and optical profilometry (Altimet). Both C-AFM and SKPFM are newer techniques, linked to AFM, which can help in understanding local differences in electrochemical nature between various microstructure phases with sub-micrometre resolution [39-42].

\subsection{Tribo-electrochemical Measurements}

The following electrochemical techniques were applied: potentiodynamic polarization (PD), potentiostatic polarization $(\mathrm{P})$, cyclic polarization $(\mathrm{CP})$, current noise monitoring at an imposed anodic potential (P-EN) and current and potential noise monitoring at free corrosion potential (ZRA-EN).

In tribocorrosion studies of passivating alloys the potentiodynamic polarization (PD) test is used to observe the effects of wear and friction on the corrosion reactions at different potentials [5]. To facilitate this observation the PD curves measured under corrosion-only and corrosive wear conditions are overlayed on one graph [3, 5, 43]. Since the position of the PD curves depends on the potential scan rate, identical scanning rates must be used for valid comparisons. In this study, all PD tests were conducted with the scan rate of $1 \mathrm{mV} / \mathrm{s}$, with the potential sweep starting at about $0.1 \mathrm{~V}$ below the open circuit potential (OCP). As the potential is swept from the cathodic to the anodic values, the corresponding corrosion processes also change. In multiphase materials it can mean a switch from anodic to cathodic behaviour between the phases. A big disadvantage of potentiodynamic tests is a non-steady corrosion state due to gradually increasing potentials. One way to provide better control over corrosion reactions is to conduct potentiostatic tests.

In potentiostatic polarization, a constant potential (usually anodic) is maintained on the wear sample (WE) by a potentiostat. During potentiostatic tests the evolution of current with time is monitored and the currents with and without concurrent abrasion are compared [5]. Despite various uncertainties, in some cases potentiostatic tests allow for quantifying the amount of corroded metals [44].

Cyclic polarization (CP) is an electrochemical technique that can indicate the susceptibility of a passive alloy to a localized corrosion, such as pitting or crevice, in a specific environment. To generate a CP curve, the potentiodynamic scan is run in both forward and reverse directions. The presence of positive hysteresis means that the transpassive 
film damage is not repaired on the reverse scan and stable localized corrosion is possible [45]. In this study, the forward potential scan began at $0.1 \mathrm{~V}$ below the OCP and the potential was increased at a rate of $1 \mathrm{mV} / \mathrm{s}$ until the current density reached $0.5 \mathrm{~mA} / \mathrm{cm}^{2}$. Then the scanning direction was reversed and the potential was decreased at a rate of $0.5 \mathrm{mV} / \mathrm{s}$ concluding at the OCP.

EN is defined as spontaneous or natural fluctuations of the potential or current of a corroding electrode. Two methods based on measuring EN have been used in this study: (1) monitoring galvanic current and potential noise (ZRA-EN) of a freely corroding metal; and (2) monitoring current noise at an imposed anodic potential (P-EN) [5]. The changes in the average values of current and potential and the amplitude of EN can elucidate some information on the corrosion processes [17]. Of special interest to this study is the ability of the EN technique to detect localized corrosion [46-48].

In the ZRA-EN method two nominally identical samples are connected to a zero-resistance ammeter (ZRA) (see Fig. 1). Theoretically, when both samples corrode freely there is no current flowing between them as both samples are at the same potential [5]. Practically, small currents are usually recorded between freely corroding multiphase samples since it is very difficult to prepare both samples with identical surface microstructures. Abrasion changes the potential of the wear sample (WE). As a result, the galvanic current flows between the abraded sample and the unworn sample (CE). This tribocorrosion current is measured with a ZRA and the potential of the wear sample is measured against a reference electrode (SSE). Compared to the potentiodynamic or potentiostatic polarization test, a big advantage of the ZRAEN method is that the current and potential are measured when the material corrodes at free corrosion potential or at conditions similar to those found in industrial systems.

Each P-EN and ZRA-EN test run consisted of four stages with different operating conditions: (1) corrosiononly stage where the disc rotates but is not in contact with the wear sample; (2) silica particles are introduced into the narrow gap between the rotating disc and the wear sample, but the sample remains unloaded; (3) the wear sample is loaded and abrasion corrosion begins; (4) the sample is unloaded but the particles continue to flow. All four stages are schematically illustrated in Fig. 3.
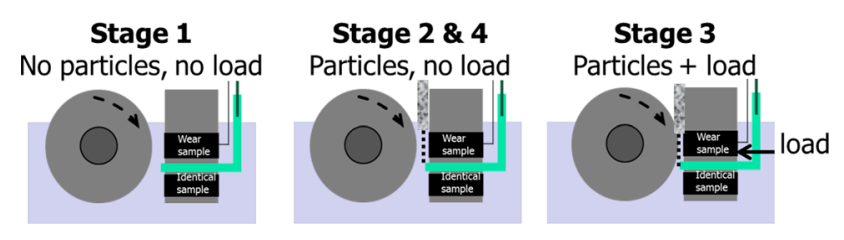

Fig. 3 Schematic illustration of the operating conditions in P-EN and ZRA-EN tribocorrosion tests

\section{Results and Discussion}

\subsection{Potentiodynamic Polarization Tests Under Corrosion-Only and Abrasion Corrosion Conditions}

Figure 4 compares potentiodynamic polarization (PD) curves of a $30 \mathrm{CrWCI}$ sample tested in a $0.01 \mathrm{M}$ sodium hydroxide $(\mathrm{NaOH})$ solution under corrosion-only (no abrasion) and abrasion corrosion conditions. Garnet particles with sizes between 212 and $300 \mu \mathrm{m}$ were used as abrasive grits. The multiphase 30CrWCI wear sample containing about $46 \mathrm{vol} \%$ carbides behaves as a heterogeneous mixed electrode and its surface spontaneously passivates in the solution tested. A low corrosion current density of $0.3 \mu \mathrm{A} / \mathrm{cm}^{2}$ was measured by polarization resistance (uniform corrosion was assumed). Since the currents measured under abrasion corrosion depend on the ratio of worn-to-unworn surface area (anode-to-cathode area ratio), the PD measurements began once the wear had reached steady-state conditions [14]. Although passivity in multiphase alloys is not well defined, the terms 'passivity' and 'passivation' are used in this study to indicate relatively low anodic currents measured for 30CrWCI under specific environment and potential conditions. An attempt at characterizing oxide films formed on the surface of 30CrWCI in air is briefly described in Sect. 3.5.

It can be seen in Fig. 4 that under abrasion corrosion the current increased by about one order of magnitude and the corrosion potential, $E_{\text {corr }}$, shifted in the cathodic direction by about $0.1 \mathrm{~V}$ compared to the corrosion-only values. However, the local distribution of $E_{\text {corr }}$ is unknown. Such behaviour is expected from passive alloys undergoing mechanical wear in aqueous solutions, either under sliding tribocorrosion [5, 43] or erosion corrosion conditions [49]. Sliding tribocorrosion tests have shown that, for nominally identical wear conditions, the alloys with very good

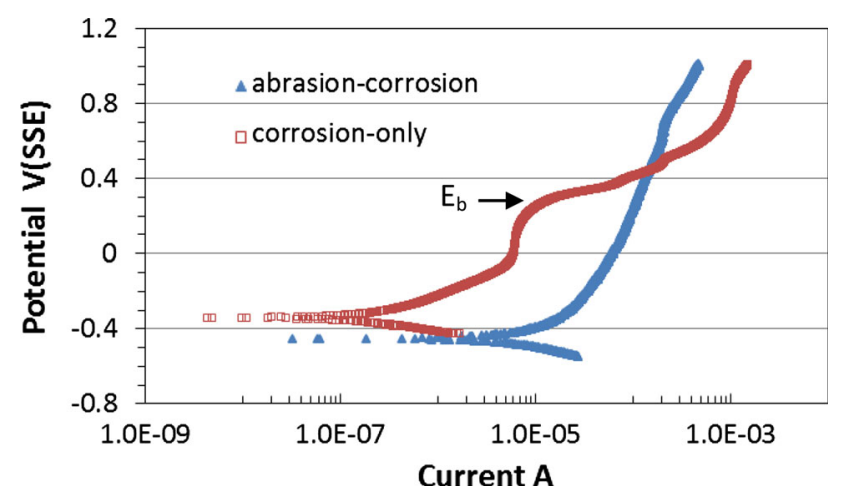

Fig. 4 Corrosion-only and abrasion corrosion PD curves of 30CrWCI in $0.01 \mathrm{M} \mathrm{NaOH}$; scan rate $1 \mathrm{mV} / \mathrm{s}$, sample area $1.13 \mathrm{~cm}^{2}, 212-300 \mu \mathrm{m}$ garnet abrasives, $2 \mathrm{~N}$ load (adapted from ref [14]) 
passivating characteristics display bigger changes in the currents measured and corrosion potentials shifts compared to the alloys with weaker passivity [43]. However, since the magnitude of current increase depends on the worn-tounworn area ratio, such comparisons are valid if these area ratios are similar for all the alloys tested [5, 50]. Taking into account that the worn-to-unworn area ratio in Fig. 4 is quite high ( $\approx 0.6$, based on profilometry measurement), the relatively small magnitude of the current change suggests that the oxide films formed on the hypereutectic 30CrWCI in $0.01 \mathrm{M} \mathrm{NaOH}$ provide a level of corrosion protection that is not as good as that provided by, e.g. compact passive films formed on type 304 or 316 stainless steels [43]. High current oscillations on PD curves are often recorded in corrosive wear studies of alloys that readily repassivate in the electrolyte tested $[8,43]$. Since significant current oscillations are absent in the abrasion corrosion PD curve in Fig. 4, this suggests that the reoxidation of the surface films on $30 \mathrm{CrWCI}$ in $\mathrm{pH} 12$ might be impaired during wear.

It is interesting to note that the breakdown potential $E_{\mathrm{b}}$ of about $0.3 \mathrm{~V}$ (SSE) visible on the corrosion only PD curve in Fig. 4 is absent on the corresponding abrasion corrosion curve. Also, at potentials higher than $0.4 \mathrm{~V}$ (SSE) the corrosion-only current is higher than the abrasion corrosion current. Comparison of the 30CrWCI surfaces after the corrosion-only and abrasion corrosion PD tests revealed a possible reason behind these characteristics and the respective SEM images are shown in Fig. 5.

Although the oxidizing potentials above the $E_{\mathrm{b}}$ cause transpassivity over the entire surface of $30 \mathrm{CrWCI}$, it appears from Fig. 5a that the carbides are attacked more severely than the matrix and a thick oxidized layer on the carbides is fractured. Although it is clear that corrosion proceeds non-uniformly, the relative contribution of the galvanic coupling effects is hard to determine. It is likely that at high anodic potentials the dissolution rate of the carbides is higher than that of the matrix and the carbides contribute more to the transpassive current. At the high potentials under abrasion corrosion conditions the thick oxidized layer is removed from the carbides present in the wear scar area. At the same time the matrix is plastically deformed and is often spread over the carbide-depleted regions, as seen in Fig. 5b. This alters the microstructure composition of the wear scar and probably affects the tribocorrosion characteristics. Since the carbides covered by the matrix are not available for transpassive dissolution, the corrosion kinetics at high potentials depends largely on the matrix response to abrasion corrosion.

It is now generally agreed that the usefulness of PD curves in tribocorrosion studies is limited and is mainly of the qualitative nature. The advantages include rapid screening of various alloys and the confirmation of active or passive behaviour [5, 14, 43]. For a particular passivating alloy, the magnitudes of the shift to higher currents measured and to more cathodic $E_{\text {corr }}$ depend on many variables: the ratio between worn and unworn areas, their respective potentials, the fraction of the depassivated area inside the wear scar, the experimental set-up geometry, operating conditions and the material's electrochemical properties [5, 14, 43]. Since many of the variables are difficult to determine, the PD tests cannot be used for quantitative assessments of tribocorrosion behaviour $[3,5]$.

\subsection{Abrasion Corrosion Potentiostatic Polarization Tests}

Potentiostatic polarization tests were performed in two solutions: electrolyte $\mathrm{C}$ (synthetic solution simulating the (a)

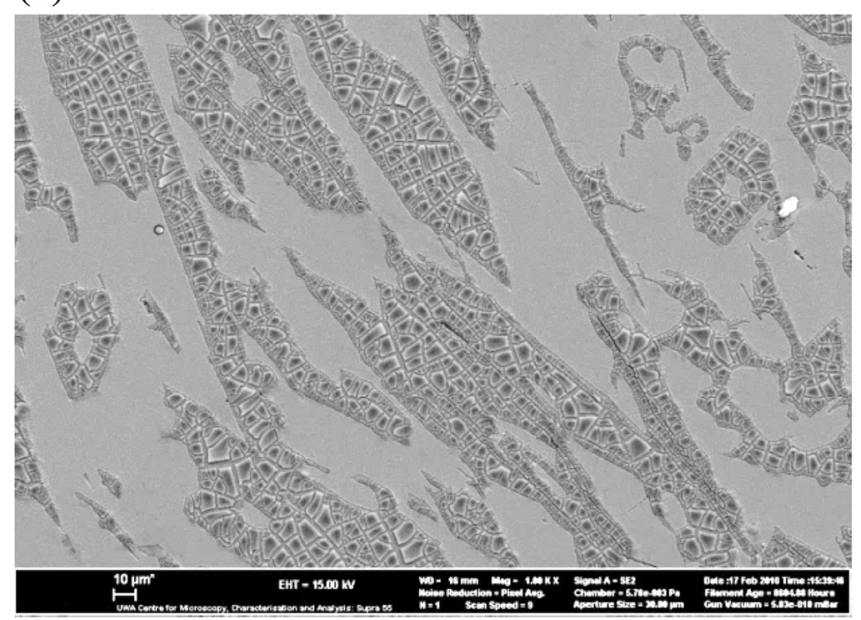

(b)

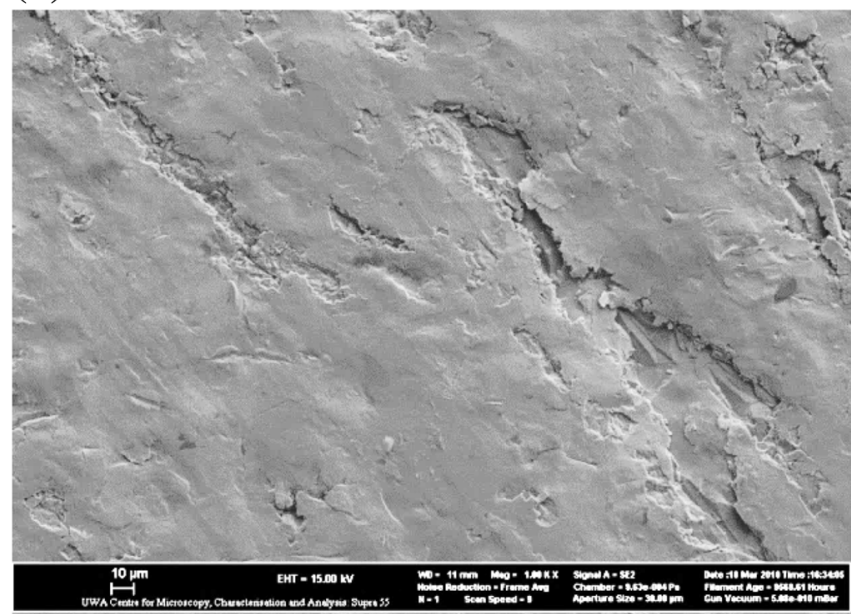

Fig. 5 Secondary electron SEM images of the 30CrWCI surface after (a) corrosion-only and (b) abrasion corrosion PD tests in $0.01 \mathrm{M}$ NaOH; 212-300 $\mu \mathrm{m}$ garnet abrasives, $2 \mathrm{~N}$ load. Both surfaces were polarized up to $1 \mathrm{~V}$ (SSE) 
Bayer process liquid) and electrolyte $\mathrm{D}$ (composition similar to electrolyte $\mathrm{C}$ but without $\mathrm{NaOH}$ ). Chemical compositions and $\mathrm{pH}$ values of the solutions are given in Table 2. The PD curves of the 30CrWCI samples in electrolytes $\mathrm{C}$ and $\mathrm{D}$ suggest that in these solutions the alloy's passivating ability is poorer than that in electrolyte A [14]. Although very similar corrosion potentials were found in all three electrolytes, passive currents higher by about one order of magnitude were measured in electrolytes $\mathrm{C}$ and $\mathrm{D}$ compared to that in electrolyte A [14]. Each potentiostatic test consisted of the initial unloaded phase where the wear sample was allowed to corrode at the imposed anodic potential until steady conditions were attained. This was followed by an abrasion corrosion stage and finished with a short unloaded corrosion stage. The imposed potentials were maintained at about $0.1 \mathrm{~V}$ above the OCP, in electrolyte $\mathrm{C}$ at $-300 \mathrm{mV}$ (SSE), while in electrolyte $\mathrm{D}$ at
$-100 \mathrm{mV}$ (SSE). Figure 6 compares the evolution of current with time of the 30CrWCI samples in both solutions.

It can be seen in Fig. 6 that during the initial stage, when the samples were corroding without abrasion, the current had quickly reached a stable level and current fluctuations were low in both electrolytes. Once the abrasion commenced, the current gradually increased. In the highly alkaline electrolyte $\mathrm{C}(\mathrm{pH}>14$, Fig. 6a) the current measured under abrasion corrosion and its rate of increase were much lower than those in electrolyte $\mathrm{D}$ ( $\mathrm{pH} \approx 11$, Fig. $6 \mathrm{~b}$ ). Comparison of optical profilometry scans of the worn surfaces revealed that the corresponding surface damage was also different [14]. After abrasion in electrolyte $C$ the wear surface damage was rather uniform over the wear scar. On the other hand, after abrasion in electrolyte D localized areas with deeper wear were found. Representative SEM images of the worn surfaces, shown in Fig. 7, illustrate these differences. (a)

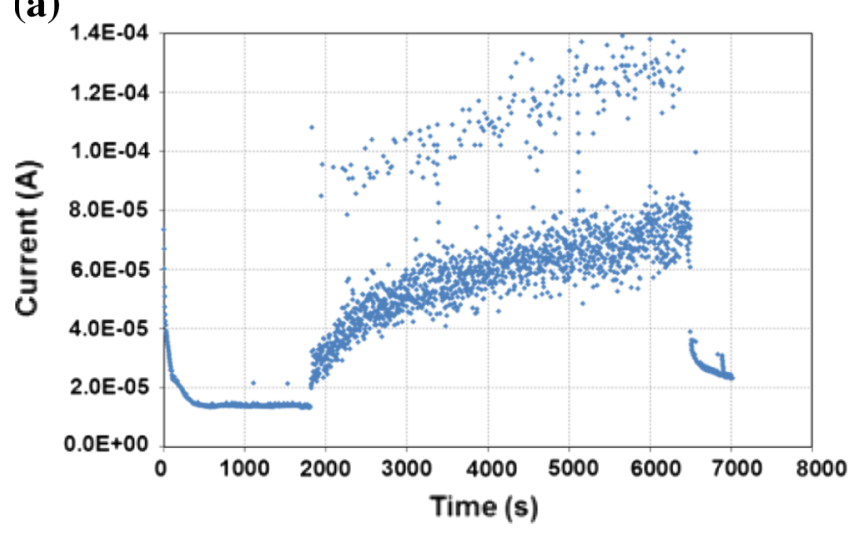

(b)

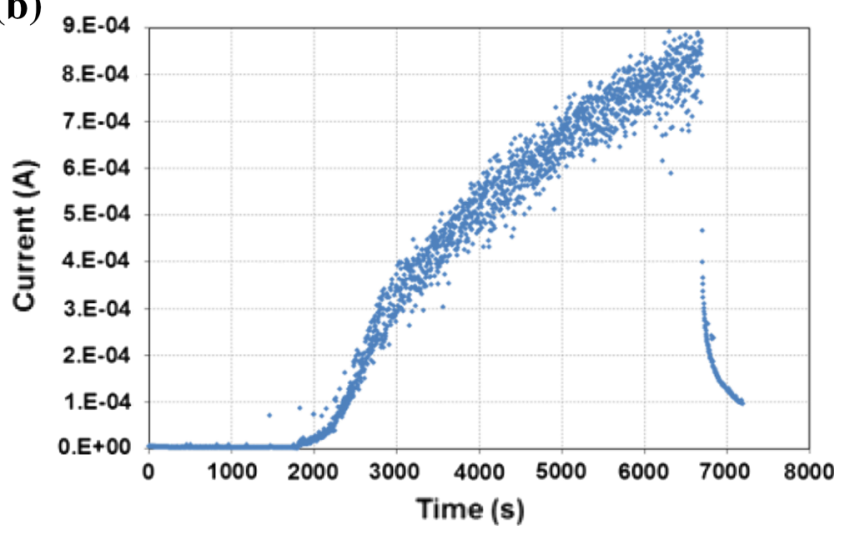

Fig. 6 Evolution of the current measured with time of 30CrWCI samples during abrasion corrosion in a electrolyte C, imposed potential $-300 \mathrm{mV}$ (SSE) and b electrolyte D, imposed potential -100 mV (SSE); sample area $1.13 \mathrm{~cm}^{2}, 212-300 \mu \mathrm{m}$ garnet abrasives, $2 \mathrm{~N}$ load

(a)

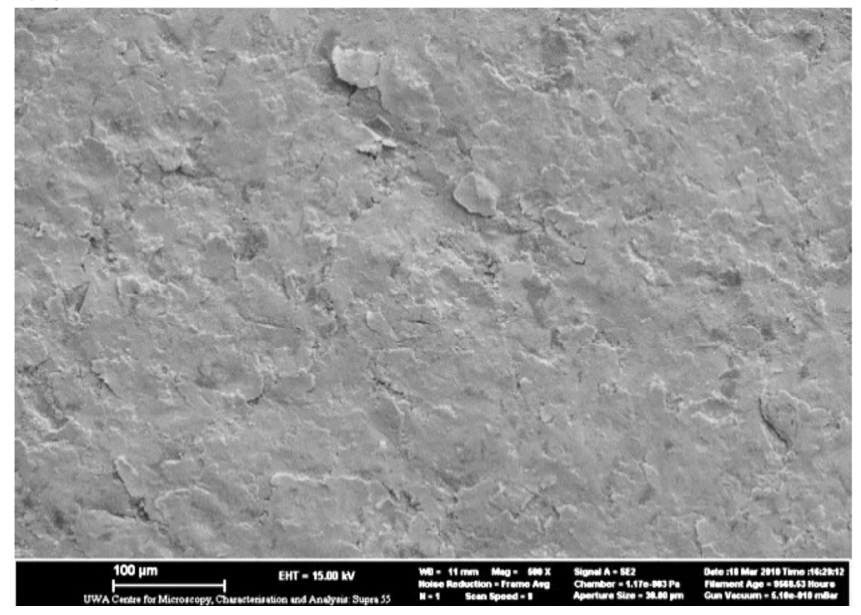

(b)

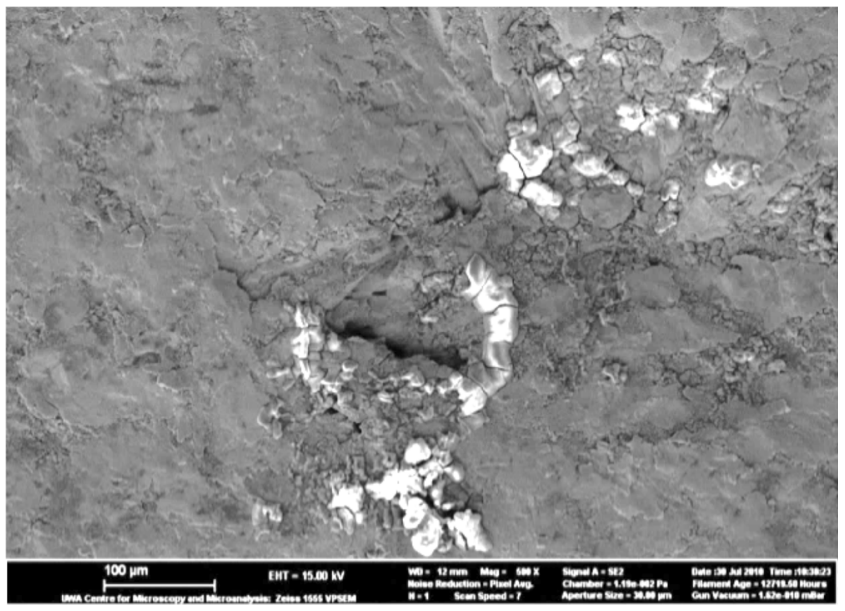

Fig. 7 Secondary electron SEM images of the 30CrWCI wear morphology, taken from the middle of the wear track, after potentiostatic abrasion corrosion tests in a electrolyte $\mathrm{C}$, imposed potential $-300 \mathrm{mV}$ (SSE) and b electrolyte D, imposed potential $-100 \mathrm{mV}$ (SSE) 
The difference between the potentiostatic currents measured with and without abrasion can be used to indicate severity of the wear-accelerated corrosion at the imposed potential. This approach is valid provided the potentiostatic current measured is equal to the anodic dissolution current (oxidation of metal) and other anodic and cathodic reactions are negligible [3, 5]. Accounting for all possible reactions is often complicated due to e.g. changes to the solution's chemistry during testing or differences between applied and actual working electrode potentials caused by high ohmic drops [5]. Assuming that the potentiostatic current measured when the 30CrWCI sample was abraded in electrolytes $\mathrm{C}$ and $\mathrm{D}$ is due largely to metal oxidation, and provided that both wear scar areas are very similar, it can be predicted, based on Fig. 6, that the contribution of the wear-accelerated corrosion would be higher in electrolyte D. While measuring the potentiostatic current is relatively straightforward, converting the current measured to mass loss and corrosion rates poses problems [3,5]. Application of Faraday's law to calculate the dissolved mass of metal in alloys requires knowledge of the alloys chemical composition and valence states of all metals contributing to the dissolution current. Representing corrosion rates in terms of current densities is hindered by uncertainty in estimating the corroding area. Since the wear scar is composed of continuously changing mixture of depassivated and repassivating sites, and the fraction of the depassivated area is hard to determine, the corrosion current densities under abrasion can be underestimated when the entire wear scar area in used in calculation. In multiphase alloys such as high-Cr WCIs the uncertainty is compounded by the non-uniform characteristics of the passive film covering the surface [37].

\subsection{Cyclic Polarization Tests}

Since it is known that passive films based on chromium oxide are prone to localized passivity breakdown in the presence of chloride ions, the authors designed a series of cyclic polarization $(\mathrm{CP})$ tests to investigate if high-Cr WCIs display this susceptibility [15]. It was found that the addition of chloride ions to alkaline solutions in which 30CrWCI would otherwise spontaneously passivate $(\mathrm{pH} \approx 12)$ might cause localized matrix corrosion at the matrix/carbide boundaries [15]. Figure 8 compares CP curves of the $30 \mathrm{CrWCI}$ sample in a $0.01 \mathrm{M} \mathrm{NaOH}$ solution with and without chloride ions.

It can be seen in Fig. 8 that while 30CrWCI repassivates on the reverse scan and is not prone to pitting or other localized corrosion in a chloride-free $0.01 \mathrm{M} \mathrm{NaOH}$ solution, it becomes susceptible to localized corrosion when chloride ions in concentration of $500 \mathrm{mg} / \mathrm{l}$ are added. To investigate if this susceptibility to localized corrosion still

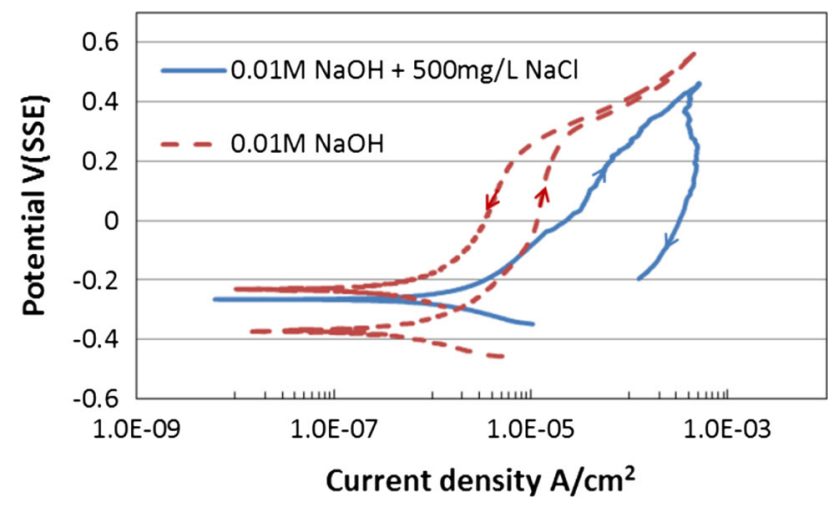

Fig. 8 Cyclic polarization curves of 30CrWCI in $0.01 \mathrm{M} \mathrm{NaOH}$ and $0.01 \mathrm{M} \mathrm{NaOH}+500 \mathrm{mg} / \mathrm{l} \mathrm{NaCl}$; the arrows indicate the scan direction

occurs under abrasion corrosion and if it can be detected, methods based on EN measurements have been explored.

\subsection{EN Measurement During Abrasion Corrosion (ZRA-EN and P-EN Tests)}

Figure 9 shows the evolution of galvanic current and potential with time when two $30 \mathrm{CrWCI}$ samples were connected galvanically and immersed in $0.01 \mathrm{M} \mathrm{NaOH}$ containing $500 \mathrm{mg} / \mathrm{l} \mathrm{NaCl}$. Semi-angular silica sand particles with average sizes between 150 and $212 \mu \mathrm{m}$ were used as abrasives. The four stages of the ZRA-EN test, described in Sect. 2.3 and schematically shown in Fig. 3, are also marked in Fig. 9.

Minimal current and potential noise recorded under corrosion-only conditions (stage 1 in Fig. 9) indicates that the unloaded freely corroding 30CrWCI sample retains passivity in $0.01 \mathrm{M} \mathrm{NaOH}$ with $500 \mathrm{mg} / \mathrm{l}$ of chloride ions. The introduction of abrasive particles into the gap (stage 2) coincides with the appearance of low-amplitude current transients. The negative direction of the transients suggests that some disturbance of the passive layer might be occurring mainly on the counter electrode made of the same 30CrWCI material. Once the wear sample is loaded and abrasion begins (stage 3) there is an instantaneous increase in the anodic current and a concurrent decrease in the potential due to the tribocorrosion damage (depassivation) on the wear sample. The average current gradually increases and the potential decreases until steady-state conditions are reached.

Compared to stages 1 and 2, the amplitudes of the current and potential noise during stage 3 are much higher. Two types of current noise can be distinguished in Fig. 9: regular fluctuations around the average value and distinct transients. The regular current fluctuations are due to numerous events of passive film breakdown by abrasive 
Fig. 9 Galvanic current and potential evolution of $30 \mathrm{CrWCI}$ in $0.01 \mathrm{M} \mathrm{NaOH}+500 \mathrm{mg} / \mathrm{l}$ $\mathrm{NaCl}$; ZRA-EN method, $150-212 \mu \mathrm{m}$ silica grits, load $0.34 \mathrm{~N}$
ENZRA pH 12 with 500 mg/ $\mathrm{L} \mathrm{Cl}^{-}$

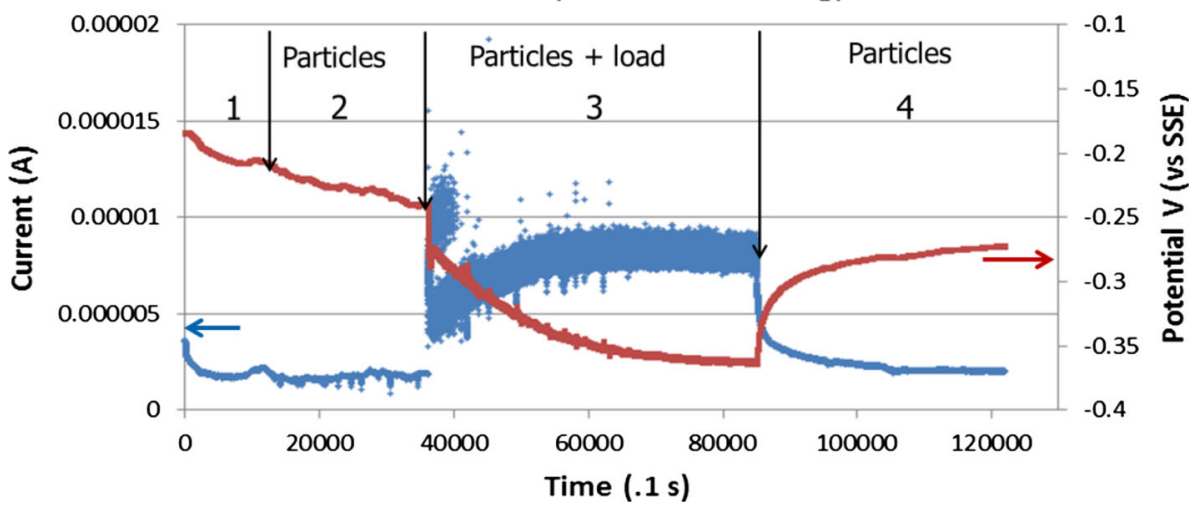

particles followed by repassivation [17]. These fluctuations appear to be similar to the current noise observed during erosion corrosion of stainless steel [51]. The distinct current transients with higher amplitude might indicate instances of unstable pitting or other localized corrosion events. High amplitude transients were not observed when abrasion was carried under conditions where the 30CrWCI sample was not susceptible to pitting [15]. It is interesting to note that the current transients are not present in the second half of stage 3, during the steady-state tribocorrosion. After subsequent unloading (stage 4 ) both the current and the current noise decrease to the initial levels, suggesting that the passivity has been restored.

A similar test was conducted using a potentiostatic method (P-EN) where the anodic current evolution with time and current noise were measured at an imposed anodic potential of $0 \mathrm{mV}$ (SSE). This potential value was selected to provide oxidizing conditions that would facilitate stable passivity breakdown on the wear sample [15]. Figure 10 shows the changes in the current and current noise during the four stages of the test run. It can be seen in Fig. 10 that stable localized passivity breakdown is likely to occur even during stage 2 when the particles flow freely in the narrow gap between the rotating disc and the unloaded wear sample. Indeed, steady increase in the current observed during the second half of stage 2 indicates that some local breakdown of the passive film might have turned into growing pits. Stable localized corrosion in stage 2 is mainly due to the anodic potential being set above the repassivation potential.

On loading the sample (the beginning of stage 3), the steady increase in current is initially halted before the current increases again, albeit at a slower rate. It appears that the abrading action by the particles interrupts the pitting propagation or even stops it. Numerous current transients observed during the entire stage 3 may indicate a competition between the passivity breakdown driven by the high potential and surface abrasion by the loaded particles.
Despite the presence of current transients the average current stabilizes. It seems that the surface abrasion might be even beneficial in preventing the stable growth of pits or crevices.

Unloading (stage 4) is accompanied by a brief current drop, but then the current continues to increase and the transients are present. The steady increase in current at a rate higher than that in stage 3 , but similar to that in stage 2 , indicates that stable localized corrosion can proceed again without interruption from abrasion. It should be noted that this behaviour is much different to that observed in stage 4 when the test was conducted at the corrosion potential (see Fig. 9). The results presented in Figs. 9 and 10 illustrate the usefulness of the EN method in investigating the effects of abrasion on localized corrosion. The application of the EN method in tribocorrosion studies of multiphase alloys will be continued by the authors with the aim to provide new experimental evidence.

SEM images of the worn surfaces after ZRA-EN and P-EN tests are compared in Fig. 11. Figure 11a shows that during the ZRA-EN abrasion corrosion tests the material was removed by plastic deformation of the matrix and microcracking of the carbides and there is no evidence of stable localized corrosion. In contrast, as confirmed in Fig. 11b, the presence of localized corrosion was found on the worn surface after the P-EN abrasion corrosion tests. Based on the presence of current transients and a continuous current increase observed in stage 4 in Fig. 10 it seems likely that most of the stable localized corrosion proceeded after the wear sample unloading. It is also interesting to note that the severity of the matrix dissolution along matrix/carbide boundaries is not uniform over the wear scar area. It has therefore been speculated that the distribution of chromium in the matrix is not homogeneous and the regions with $\mathrm{Cr}$ depletion are prone to passivity breakdown [15]. This hypothesis was investigated using high-resolution surface analysis methods and the results are described in Sect. 3.5. 
Fig. 10 Potentiostatic current evolution of $30 \mathrm{CrWCI}$ in $0.01 \mathrm{M} \mathrm{NaOH}+500 \mathrm{mg} / \mathrm{l}$ $\mathrm{NaCl}$; P-EN method at anodic potential $0 \mathrm{~V}$ (SSE),

150-212 $\mu \mathrm{m}$ silica grits, load $0.34 \mathrm{~N}$

(a)

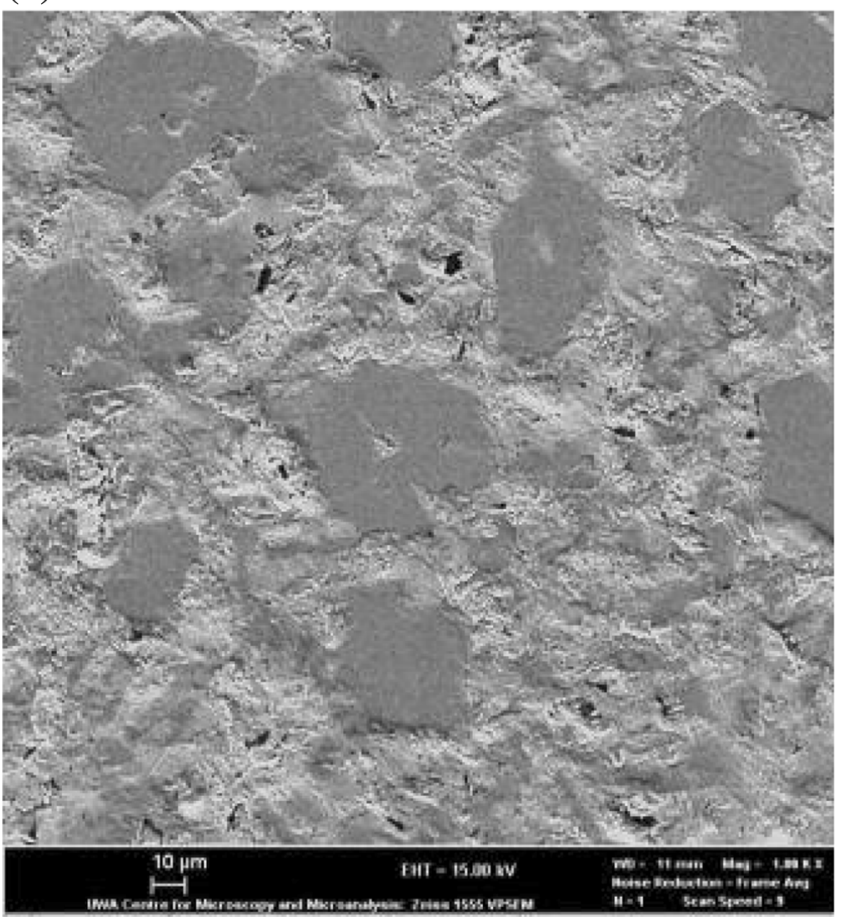

PECN pH 12 with $500 \mathrm{mg} / \mathrm{L} \mathrm{Cl}^{-}$at $0 \mathrm{mV}$ (SSE)

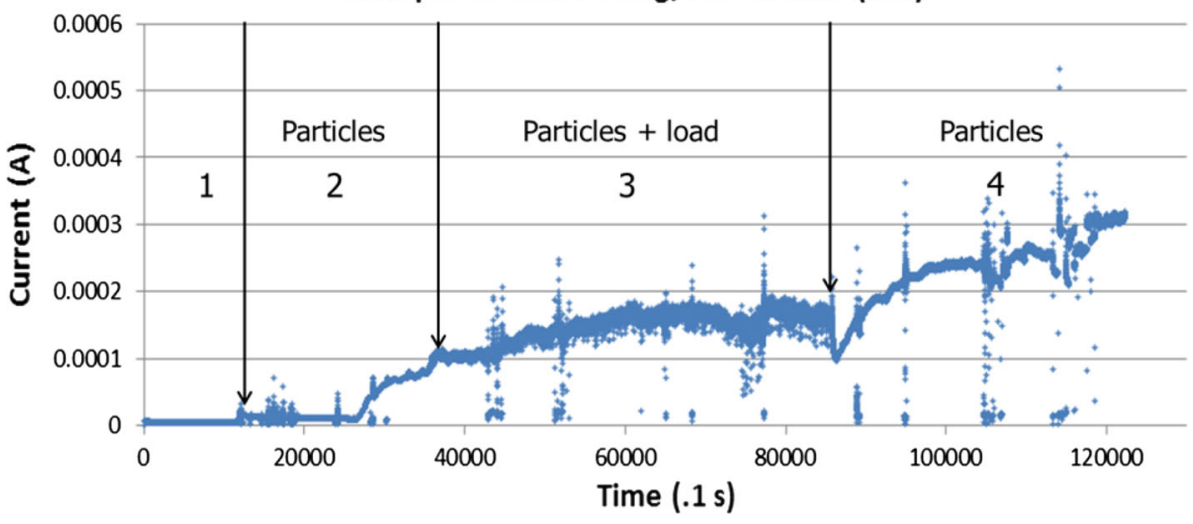

(b)

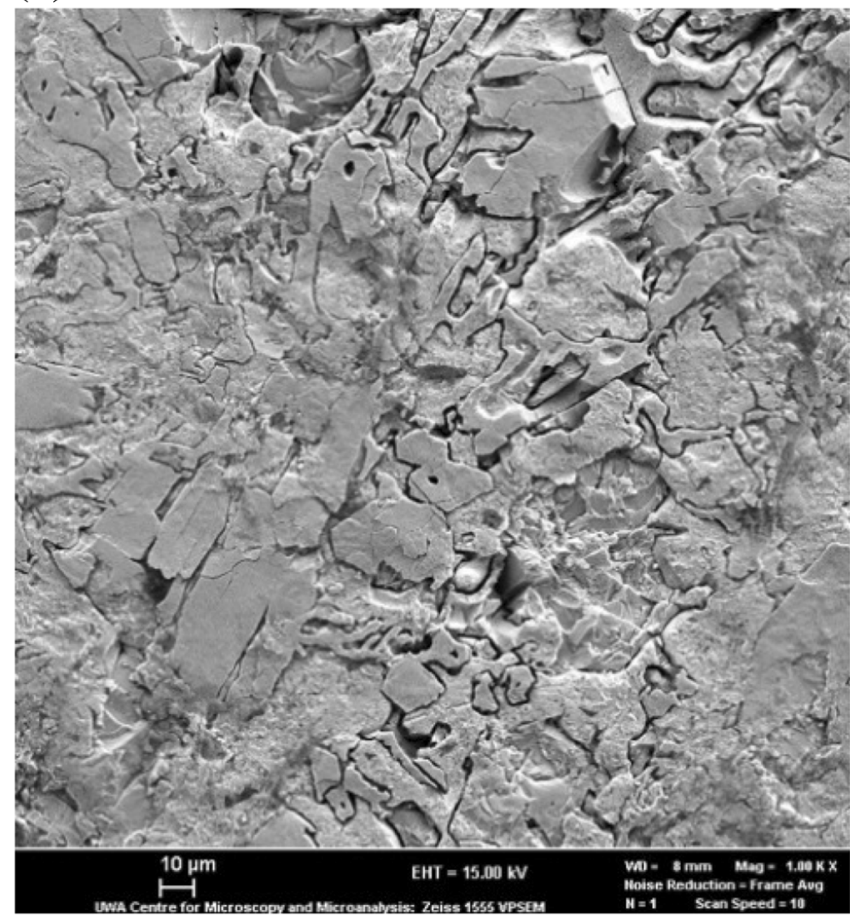

Fig. 11 Secondary electron SEM images comparing the worn surfaces of 30CrWCI after a ZRA-EN and b P-EN abrasion corrosion tests

For comparison, abrasion corrosion characteristics of 30CrWCI in a chloride-containing near neutral solution (electrolyte E in Table 2) were investigated using a ZRA-EN method and the results are shown in Fig. 12. As can be seen in Fig. 12, in a solution containing $500 \mathrm{mg} / \mathrm{l} \mathrm{NaCl}$ a 30CrWCI sample behaves much differently during the four stages of the test compared to the behaviour observed in alkaline solutions (pH 12) with the same concentration of chlorides (Fig. 9). In electrolyte E, 30CrWCI does not passivate and the matrix dissolves in preference to the carbides [15].

Noisy small current in stage 1 of the test indicates some corrosion activities on the samples at the corrosion potential. Introduction of freely flowing particles into the gap (stage 2) causes a sudden current shift to the positive values, followed by a gradual current decline. Loading the wear sample (stage 3 ) is accompanied by a small current shift in the negative direction and then the current continues to decrease until it reaches a level similar to that measured in stage 1 . On unloading the wear sample the current jumps in the positive direction and then declines again. In contrast to the 30CrWCI sample behaviour in the alkaline electrolyte with chlorides (Fig. 9), the highest noise in the neutral solution was observed during the initial free corrosion stage 1 and no high current transients were measured during any stages. There was no effect of abrasion on the wear sample potential. 
Fig. 12 Galvanic current and potential evolution of $30 \mathrm{CrWCI}$ in $500 \mathrm{mg} / \mathrm{l} \mathrm{NaCl}$; ZRA-EN method, 150-212 $\mu \mathrm{m}$ silica grits, load $0.34 \mathrm{~N}$

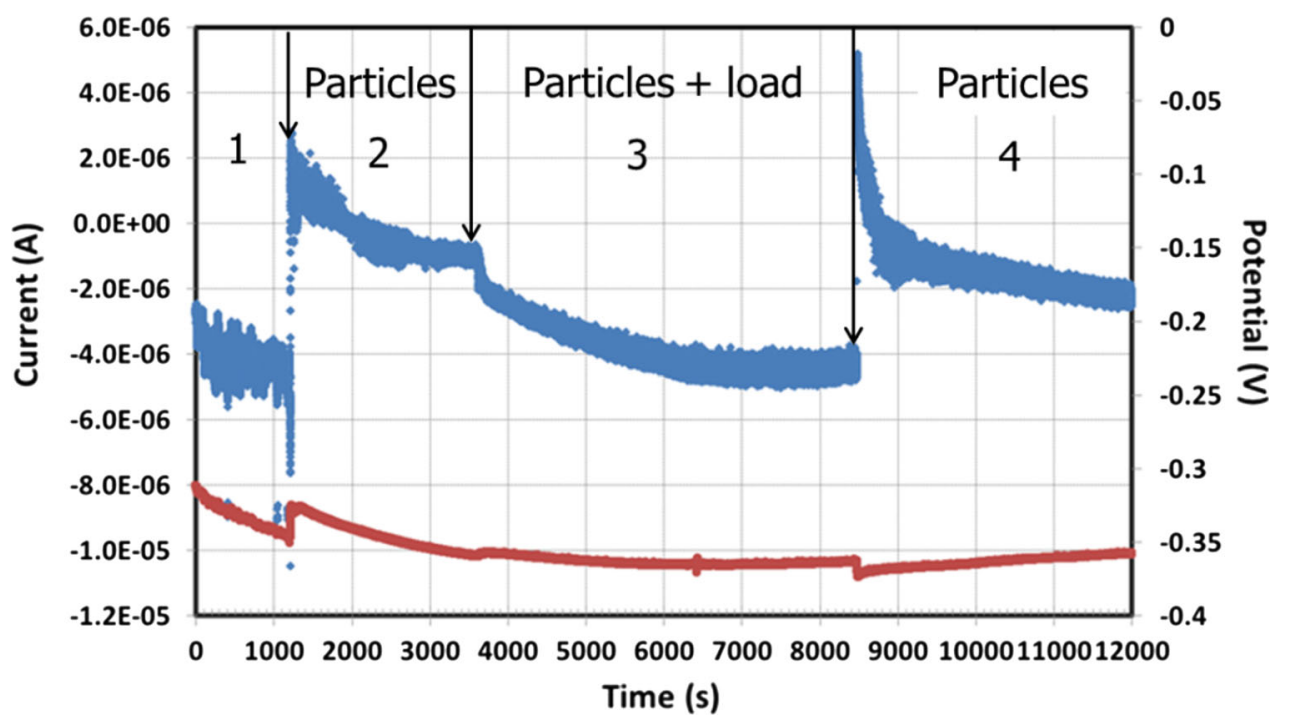

The current and potential characteristics, shown in Fig. 12, represent the behaviour expected from materials that do not passivate in the solution tested. Corrosion is not uniform; it starts at the matrix/carbide boundaries and proceeds within the matrix phase. The corrosion products cover some regions on the $30 \mathrm{Cr}$ WCI surface and underdeposit dissolution is likely to continue [15].

\subsection{High-Resolution Surface Analysis of 30CrWCI}

To fully understand the response of each microstructure phase to corrosion and to a combined action of abrasion and corrosion, high-resolution electron microprobe (EMPA), NanoSIMS, C-AFM and SKPFM techniques have been used. The main purpose was to ascertain if the regions of $\mathrm{Cr}$ depletion exist along the carbide/matrix boundaries. In highCr WCIs chromium plays the major role in the passive film formation and at least $12 \mathrm{wt} \%$ of $\mathrm{Cr}$ dissolved in the matrix is needed to provide 'stainless' characteristics required in industrial applications [52].

Quantitative EMPA measurements determined that although the $\mathrm{Cr}$ content in the matrix distanced from the carbide/matrix boundaries remains at around 11.5-12.5 wt $\%$ (sufficient to form a chromium oxide-based passive film), in the vicinity of the boundaries it can drop to $9.5 \mathrm{wt} \%$ [37]. A more sensitive NanoSIMS technique has confirmed the EMPA results [37]. A novel approach to the SIMS method, which included a deposition of a thin layer of cesium prior to implanting primary ions, allowed the authors to resolve the discrete oxide sub-layers [37]. Based on the NanoSIMS mapping of negative ions the authors proposed a model of the passive oxide films formed in air on the surface of 30CrWCI [37]. It was found that a thicker film (average thickness $\sim 2 \mathrm{~nm}$ ) covered the matrix while a thinner and less coherent film was formed on the carbides. The chromium oxide-based film covering the matrix was highly enriched in iron and displayed structural characteristics similar to those found in stainless steels with moderate passivity [53]. A major weakness in the passive layer along the carbide/matrix boundaries, due to the $\mathrm{Cr}$ concentration dropping below $10 \mathrm{wt} \%$, was detected. Schematic diagram in Fig. 13 illustrates the mechanism of passivity breakdown that is initiated along the carbide peripheries and is followed by crevice corrosion. The mechanism explains the incidences of localized corrosion the authors observed when testing 30CrWCI under specific environmental conditions [14, 15, 37].

The authors have also explored how tribocorrosion studies of multiphase alloys can benefit from two AFMbased techniques, C-AFM and SKPFM. The SKPFM results are briefly described since this technique is less known to the tribocorrosion community. The SKPFM method was used to determine the local variation of Volta potential on the surface of 30CrWCI sample. It was shown by others that the Volta potential of metals is often linearly proportional to their respective corrosion potential [41, 54]. Thus, the SKPFM maps could assist in differentiating various phases present in multiphase alloys by their nobilities. Figure 14 shows AFM topography and SKPFM Volta potential maps of a small area on the 30CrWCI sample.

The topography map and the line scan in Fig. 14a indicate that surface polishing of 30CrWCI preferentially removes the matrix, leaving the carbides slightly protruding. There is no evidence in the topography line scan of narrow gaps or crevices between the carbides and the matrix. The pre-existence of narrow crevice sites has been suggested by other researchers as a possible cause of localized corrosion of high-Cr WCIs [23]. The corresponding Volta potential map and the line scan in Fig. 14b show a difference of about $0.1 \mathrm{~V}$ in the potentials between the matrix (lower) and the carbides. In addition, narrow 


\section{Pit initiation

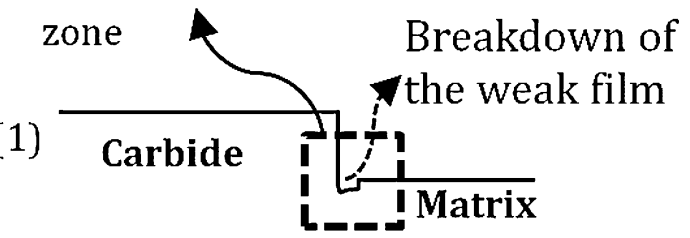

(2)

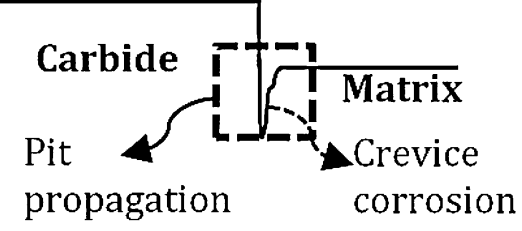

Fig. 13 Localized corrosion mechanism of 30CrWCI due to passivity impairment along carbide peripheries bands along the carbide peripheries display even lower potentials, most likely due to the lower $\mathrm{Cr}$ content in these areas. Since the Volta potentials are a measure of electrochemical nobility of different phases in air [41], the potential gradients in Fig. $14 \mathrm{~b}$ point to a possibility of micro-galvanic cells forming between the narrow boundary bands and the carbides.

\subsection{Quantitative Measurements of Synergy Between Abrasion and Corrosion in High-Cr WCIs}

The test procedure to measure wear and corrosion synergy is provided by the ASTM G119 standard: (1) the total damage is assessed by mass loss measurement after

\section{(a)}
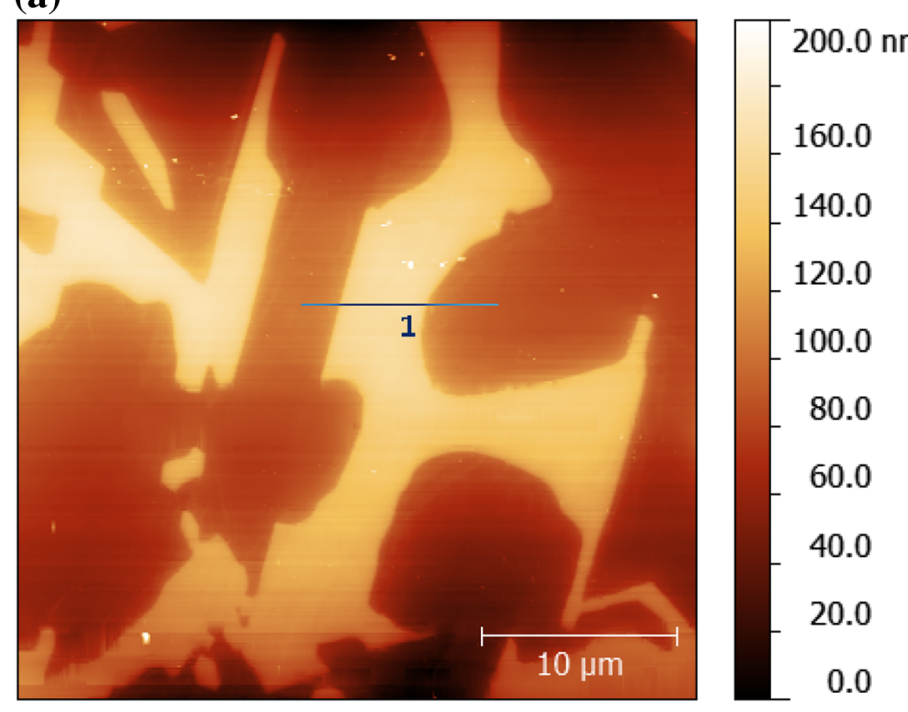

(b)
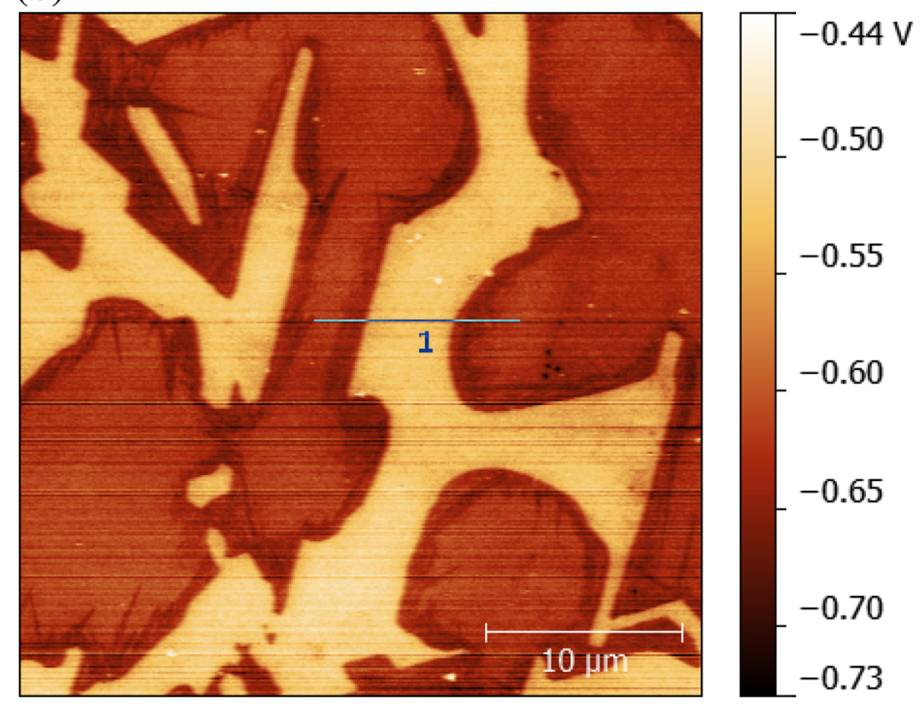
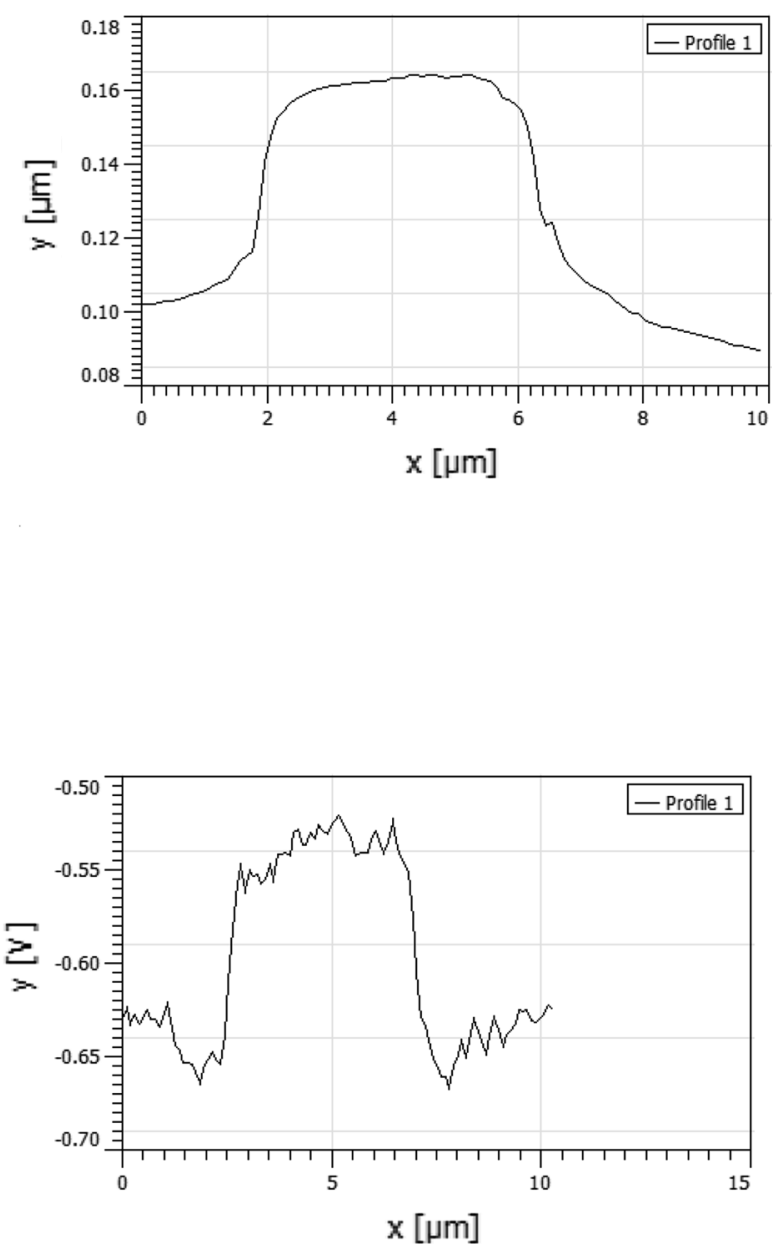

Fig. 14 a AFM topography map of the 30CrWCI surface and a line scan across the carbide/matrix boundary; b the corresponding SKPFM Volta potential map and a line scan 

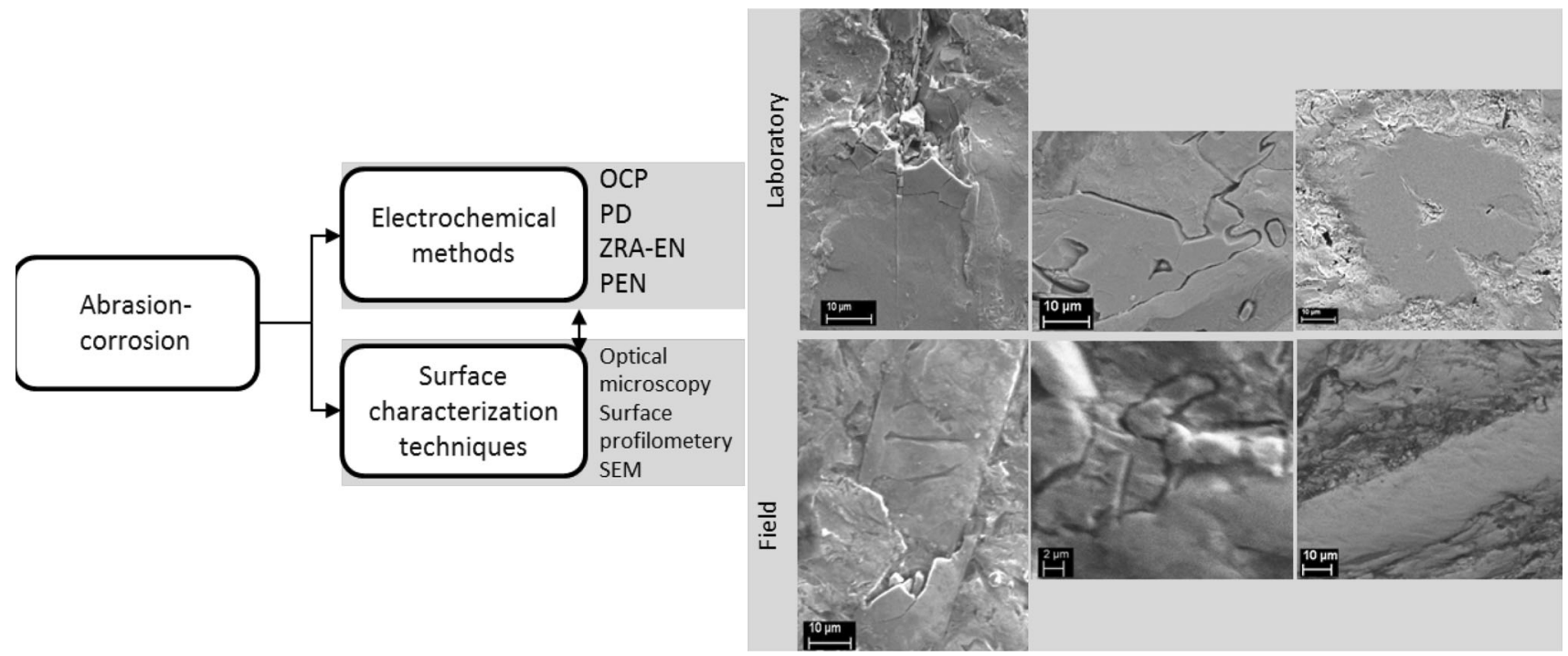

Fig. 15 Summary of the methods used to test abrasion corrosion characteristics of 30CrWCI and the comparison of surfaces worn in laboratory tests and in field

tribocorrosion testing at OCP; (2) the corrosion-only rate is determined using one of the standard methods such as polarization resistance, Tafel extrapolation or EIS; (3) the wear-only damage is measured as mass loss after tribocorrosion testing under cathodic polarization. According to the standard, this procedure works as long as corrosion is uniform. However, weighing errors can still be significant if mass losses are very small, and unexpected reactions can interfere with the wear under low cathodic potentials.

This methodology was used by others to quantify synergistic effects between corrosion and erosion of hypereutectic and near eutectic high-Cr WCIs in $3.5 \mathrm{wt} \% \mathrm{NaCl}$ [30]. The corrosion rate was measured by polarization resistance but there was no mention of the corrosion mechanism. The authors' own research has shown that high-Cr WCIs often corrode non-uniformly and the corrosion mechanisms depend on the $\mathrm{pH}$, potential and the presence of chloride ions. As already discussed in Sect. 3.4, in a near neutral solution containing $500 \mathrm{mg} / \mathrm{l}$ $\mathrm{NaCl}$ the 30CrWCI samples corrode by preferential dissolution of the matrix and the corrosion rates calculated assuming uniform corrosion are not accurate.

\subsection{Summary of Abrasion Corrosion Characteristics of High-Cr WCIs}

Figure 15 summarizes the electrochemical methods and surface characterization techniques that were used to test abrasion corrosion behaviour and to examine the worn surfaces of 30CrWCI samples. In this study mostly alkaline solutions were used. In alkaline solutions the ability of the matrix to passivate increases with increasing $\mathrm{pH}$, while the corrosion resistance of the carbides decreases. Significant carbide dissolution was observed when alkalinity was combined with a high oxidizing potential (see Fig. 5a). In moderately alkaline solutions, the regions along carbide/ matrix boundaries were susceptible to localized corrosion when the concentration of chloride ions was sufficient. Both ZRA-EN and P-EN methods were found to be able not only to detect incidences of metastable and stable localized corrosion under specific environmental conditions but also show the effect of abrasion on localized corrosion.

SEM images included in Fig. 15 show similarities between the surfaces worn during abrasion corrosion tests (laboratory) and the surfaces from industrial slurry pumps (field). The similarities in the worn surfaces indicate the relevance of laboratory abrasion corrosion testing in simulating and understanding practical tribocorrosion applications. Also, the images reveal complexity of the tribocorrosion behaviour of multiphase alloys, affected by differences in the composition and properties (material and electrochemical) between the phases.

\section{Concluding Remarks}

Tribo-electrochemical methods such as potentiodynamic and potentiostatic tests are beneficial for high-Cr WCIs as fast qualitative corrosive wear tests, useful for comparing different materials and conditions. Tribocorrosion tests utilizing current and potential noise monitoring can detect transient and stable localized corrosion phenomena that might occur in high-Cr WCIs under specific environmental 
conditions, especially those containing chloride ions. Highresolution surface analysis techniques (NanoSIMS, C-AFM, SKPFM) are very helpful not only in characterizing the minute differences in the surface layer chemical structure and composition of various microstructure phases but also in detecting the differences in their respective electrochemical nobilities. Since surface characteristics affect the chemical response of each phase to a reactive environment, understanding these differences greatly aids in predicting and explaining tribocorrosion behaviour of multiphase alloys.

This study has shown that a combination of tribo-electrochemical and surface analysis methods is often required to find out tribocorrosion mechanisms of multiphase alloys. At this stage, a generalised test protocol for testing tribocorrosion of multiphase alloys is not available yet. Also, more work is needed on the quantitative tribocorrosion methods and models applicable to complex multiphase microstructures such as those of high-Cr WCIs.

Acknowledgments The authors wish to thank the Department of Mechanical Engineering, Curtin University, for their help during writing of the manuscript. The authors also thank Dr. Thomas Becker, Nanochemistry Research Institute, Curtin University, for the AFM access and guidance and Prof Steven Reddy for help with the EBSD measurements. The authors acknowledge use of SEM and XRD at John De Laeter Centre, Curtin University and SEM at the CMCA facility, University of Western Australia.

Conflict of interest The authors declare that they have no conflict of interest.

\section{References}

1. Landolt D, Mischler S (eds) (2011) Tribocorrosion of passive metals and coatings. Woodhead Publishing Ltd., Cambridge

2. Celis J, Ponthiaux P (eds) (2012) Testing tribocorrosion of passivating materials supporting research and industrial innovation: Handbook (EFC 62), Maney Publishing, Leeds

3. Landolt D, Mischler S, Stemp M (2001) Electrochemical methods in tribocorrosion: a critical appraisal. Electrochim Acta 46:3913-3929

4. Ponthiaux P, Wenger F, Drees D, Celis JP (2004) Electrochemical techniques for studying tribocorrosion processes. Wear 256:459-468. doi:10.1016/S0043-1648(03)00556-8

5. Mischler S (2008) Triboelectrochemical techniques and interpretation methods in tribocorrosion: a comparative evaluation. Tribol Int 41:573-583

6. Wood RJK, Sun D, Thakare MR, de Frutos Rozas A, Wharton JA (2010) Interpretation of electrochemical measurements made during micro-scale abrasion-corrosion. Tribol Int 43:1218-1227. doi:10.1016/j.triboint.2010.01.004

7. Stack MM, Jawan H, Mathew MT (2005) On the construction of micro-abrasion maps for a steel/polymer couple in corrosive environments. Tribol Int 38:848-856

8. Salasi M, Stachowiak GB, Stachowiak GW (2010) New experimental rig to investigate abrasive-corrosive characteristics of metals in aqueous media. Tribol Lett 40:71-84. doi:10.1007/ s11249-010-9640-2

9. Garcia I, Drees D, Celis JP (2001) Corrosion-wear of passivating materials in sliding contacts based on a concept of active wear track area. Wear 249:452-460
10. Mischler S (2013) Sliding Tribo-Corrosion of Passive Metals: Mechanisms and Modeling. In: Blau PJ, Celis J-P, Drees D (eds) Tribo-Corrosion Res. Testing, Appl., STP 1563. ASTM International, 100 Barr Harbor Drive, PO Box C700, West Conshohocken, PA 19428-2959, pp 1-18

11. Blau PJ, Wood R, Stack MM, Mischler S, Jiang J, Drees D, Rocha LA, Wimmer MA, Celis J-P, Cowan R (2013) Future needs and challenges in tribo-corrosion research and testing. In: Blau PJ, Celis J-P, Drees D (eds), Tribo-corrosion res. testing, appl. ASTM International, 100 Barr Harbor Drive, PO Box C700, West Conshohocken, 19428-2959, pp 214-226

12. Diomidis N (2012) Towards a standard test for the determination of synergism in tribocorrosion: design of a protocol for passivating materials. In: Celis J, Ponthiaux P (eds), Testing tribocorrosion passive materials supporting research industrial innovation handbook (EFC 62). Maney Publishing, Leeds, pp 150-167

13. ASTMG119-09 (2009) Standard guide for determining synergism between wear and corrosion. doi: 10.1520/G0119-09

14. Salasi M, Stachowiak GB, Stachowiak GW (2011) Three-body tribocorrosion of high-chromium cast irons in neutral and alkaline environments. Wear 271:1385-1396. doi:10.1016/j.wear.2011. 01.066

15. Salasi M, Stachowiak GB, Stachowiak GW (2011) Chloride effect on corrosion \& corrosive wear of high-Cr cast irons in different pH solutions. 18th Int Corros Congr 2011:1335-1346

16. Keddam M, Ponthiaux P, Vivier V (2014) Tribo-electrochemical impedance: a new technique for mechanistic study in tribocorrosion. Electrochim Acta 124:3-8. doi:10.1016/j.electacta.2013. 08.186

17. Dawson J (1996) Electrochemical noise measurement: the definitive in-situ technique for corrosion applications? In: Kearns JR, Scully JR, Roberge PR, Reichert DL, Dawson JL (eds), Electrochemical noise measurement corrosion application, STP 1277. American Society for Testing and Materials, 100 Barr Harbor Drive, PO Box C700, West Conshohocken 19428-2959, pp 3-35

18. Keddam M, Oltra R, Colson JC, Desestret A (1983) Depassivation of iron by straining and by abrasion: an A.C. impedance study. Corros Sci 23:441-451. doi:10.1016/0010-938X(83)90072-0

19. Keddam M, Wenger $F$ (2011) Electrochemical methods in tribocorrosion. In: Mischler S, Landolt D (eds) Tribocorrosion of passive metals and coatings. Woodhead publishing, Cambridge, pp 187-221

20. Assi F, Bohni H (1999) Study of wear-corrosion synergy with a new microelectrochemical technique. Wear 233-235:505-514

21. Llewellyn RJ, Yick SK, Dolman KF (2004) Scouring erosion resistance of metallic materials used in slurry pump service. Wear 256:592-599

22. Walker CI (2001) Slurry pump side-liner wear: comparison of some laboratory and field results. Wear 250:81-87. doi:10.1016/ S0043-1648(01)00613-5

23. Neville A, Reza F, Chiovelli S, Revega T (2006) Characterization and corrosion behavior of high-chromium white cast irons. Metall Mater Trans A 37:2339-2347. doi:10.1007/BF02586208

24. Chang C-M, Hsieh C-C, Lin C-M, Chen J-H, Fan C-M, Wu W (2010) Effect of carbon content on microstructure and corrosion behavior of hypereutectic $\mathrm{Fe}-\mathrm{Cr}-\mathrm{C}$ claddings. Mater Chem Phys 123:241-246. doi:10.1016/j.matchemphys.2010.04.003

25. Wiengmoon A, Pearce JTH, Chairuangsri T (2011) Relationship between microstructure, hardness and corrosion resistance in 20 wt.\% Cr, 27 wt.\% $\mathrm{Cr}$ and 36 wt.\% Cr high chromium cast irons. Mater Chem Phys 125:739-748. doi:10.1016/j.match emphys.2010.09.064

26. Stachowiak GB, Stachowiak GW, Celliers O (2005) Ball-cratering abrasion tests of high-Cr white cast irons. Tribol Int 38:1076-1087. doi:10.1016/j.triboint.2005.07.035 
27. Scandian C, Boher C, de Mello JDB, Rézaï-Aria F (2009) Effect of molybdenum and chromium contents in sliding wear of highchromium white cast iron: the relationship between microstructure and wear. Wear 267:401-408. doi:10.1016/j.wear.2008.12. 095

28. Wang YP, Li DY, Parent L, Tian H (2013) Performances of hybrid high-entropy high-Cr cast irons during sliding wear and air-jet solid-particle erosion. Wear 301:390-397. doi:10.1016/j. wear.2012.12.045

29. Chung RJ, Tang X, Li DY, Hinckley B, Dolman K (2013) Microstructure refinement of hypereutectic high $\mathrm{Cr}$ cast irons using hard carbide-forming elements for improved wear resistance. Wear 301:695-706. doi:10.1016/j.wear.2013.01.079

30. Jones M, Llewellyn RJ (2009) Erosion-corrosion assessment of materials for use in the resources industry. Wear 267:2003-2009. doi:10.1016/j.wear.2009.06.025

31. Tian HH, Addie GR, Visintainer RJ (2009) Erosion-corrosion performance of high-Cr cast iron alloys in flowing liquid-solid slurries. Wear 267:2039-2047. doi:10.1016/j.wear.2009.08. 007

32. Tang XH, Chung R, Pang CJ, Li DY, Hinckley B, Dolman K (2011) Microstructure of high (45wt.\%) chromium cast irons and their resistances to wear and corrosion. Wear 271:1426-1431. doi:10.1016/j.wear.2010.11.047

33. Tang XH, Chung R, Li DY, Hinckley B, Dolman K (2009) Variations in microstructure of high chromium cast irons and resultant changes in resistance to wear, corrosion and corrosive wear. Wear 267:116-121. doi:10.1016/j.wear.2008.11.025

34. Chung RJ, Tang X, Li DY, Hinckley B, Dolman K (2011) Abnormal erosion-slurry velocity relationship of high chromium cast iron with high carbon concentrations. Wear 271:1454-1461. doi:10.1016/j.wear.2011.01.087

35. Watson SW, Madsen BW, Cramer SD (1995) Wear-corrosion study of white cast irons. Wear 181-183:469-475

36. Flores JF, Neville A, Kapur N, Gnanavelu A (2009) Erosioncorrosion degradation mechanisms of $\mathrm{Fe}-\mathrm{Cr}-\mathrm{C}$ and $\mathrm{WC}-\mathrm{Fe}-\mathrm{Cr}-$ C PTA overlays in concentrated slurries. Wear 267:1811-1820

37. Salasi M, Stachowiak GWGB, Kilburn MR (2013) NanoSIMS investigation of passive oxide films on high-Cr cast iron. Corros Sci 67:298-303. doi:10.1016/j.corsci.2012.11.003

38. Lu B, Luo J, Chiovelli S (2006) Corrosion and wear resistance of chrome white irons - a correlation to their composition and microstructure. Metall Mater Trans A 37:3029-3038. doi:10. 1007/s11661-006-0184-x

39. Rohwerder M, Turcu F (2007) High-resolution Kelvin probe microscopy in corrosion science: scanning Kelvin probe force microscopy (SKPFM) versus classical scanning Kelvin probe (SKP). Electrochim Acta 53:290-299. doi:10.1016/j.electacta. 2007.03.016

40. Souier T, Martin F, Bataillon C, Cousty J (2010) Local electrical characteristics of passive films formed on stainless steel surfaces by current sensing atomic force microscopy. Appl Surf Sci 256:2434-2439. doi:10.1016/j.apsusc.2009.10.083

41. Cook AB, Barrett Z, Lyon SB, McMurray HN, Walton J, Williams $G$ (2012) Calibration of the scanning Kelvin probe force microscope under controlled environmental conditions. Electrochim Acta 66:100-105. doi:10.1016/j.electacta.2012.01.054

42. Afshar FN, de Wit JHW, Terryn H, Mol JMC (2013) Scanning Kelvin probe force microscopy as a means of predicting the electrochemical characteristics of the surface of a modified AA4xxx/AA3xxx (Al alloys) brazing sheet. Electrochim Acta 88:330-339. doi:10.1016/j.electacta.2012.10.051

43. Latona N, Fetherston P, Chen A, Sridharan K, Dodd RA (2001) Wear-corrosion comparisons of passivating vs nonpassivating alloys in aerated $3.5 \%$ aqueous solutions of sodium chloride. Corrosion 57:884-888

44. Geringer J, Forest B, Combrade P (2006) Wear analysis of materials used as orthopaedic implants. Wear 261:971-979

45. Tait WS (1994) An introduction to electrochemical corrosion testing for practicing engineers and scientists. PairODocs Publications, Racine

46. Cottis B (2001) Interpretation of electrochemical noise data. Corrosion 57:265-285

47. Cottis $\mathrm{Ra}$ (2007) The significance of electrochemical noise measurements on asymmetric electrodes. Electrochim Acta 52:7585-7589. doi:10.1016/j.electacta.2006.12.042

48. Curioni M, Cottis R a, Di Natale M, Thompson GE (2011) Corrosion of dissimilar alloys: electrochemical noise. Electrochim Acta 56:6318-6329. doi:10.1016/j.electacta.2011.05.034

49. Neville A, Reyes M, Xu H (2002) Examining corrosion effects and corrosion/erosion interactions on metallic materials in aqueous slurries. Tribol Int 35:643-650

50. Mischler S, Ponthiaux P (2001) A round robin on combined electrochemical and friction tests on alumina/stainless steel contacts in sulphuric acid. Wear 248:211-225

51. Oltra R, Chapey B, Huet F, Renaud L (1996) Coupling of acoustic emission and electrochemical noise measurement techniques in slurry erosion-corrosion studies. In: Kearns J, Scully J, Roberge P, Reichert D, Dawson J (eds), Electrochemical noise measurements corrosion application, STP 1277. ASTM International, 100 Barr Harbor Drive, PO Box C700, West Conshohocken 19428-2959, pp 361-374

52. Newman RC, Meng FT, Sieradzki K (1988) Validation of percolation model for passivation of $\mathrm{Fe}-\mathrm{Cr}$ alloys. Corros Sci 28:523-527

53. Williams DE, Newman RC, Song Q, Kelly RG (1991) Passivity breakdown and pitting corrosion of binary alloys. Nature 350:216-219. doi:10.1038/350216a0

54. Schmutz P, Frankel G (1998) Characterization of AA2024-T3 by scanning Kelvin probe force microscopy. J Electrochem Soc 145:2285-2295 